\title{
Modelling the impact of land use and catchment characteristics on stream water quality using a Bayesian hierarchical modelling approach in the Great Barrier Reef catchments
}

\author{
$\underline{\text { S. Liu }}^{\text {a }}$, D. Ryu ${ }^{\text {a }}$ A. Western ${ }^{\text {a }}$ A. Webb ${ }^{\text {a }}$ A. Lintern ${ }^{\text {a }}$, D. Waters ${ }^{\text {b }}$, B. Thomson ${ }^{\text {c }}$ \\ ${ }^{a}$ Department of Infrastructure Engineering, The University of Melbourne, Parkville, Victoria, Australia \\ ${ }^{b}$ Department of Natural Resources and Mines, Toowoomba, Queensland, Australia \\ ${ }^{c}$ Department of Science, Information Technology and Innovation, Brisbane, Queensland, Australia
}

Email:shucil@student.unimelb.edu.au

\begin{abstract}
The near-shore ocean ecosystem is influenced by catchment runoff. The Great Barrier Reef has been experiencing significant water quality deterioration over the past 150 years, due in part to agricultural intensification and urban settlement in adjacent catchments (Thorburn et al., 2013). There is a need for us to understand the influences of catchment characteristics on stream water quality, with an aim to mitigate and manage the water quality issue in the terrestrial stream runoff derived from the adjacent Great Barrier Reef catchments. The event-based water quality monitoring data set from the Paddock to Reef Integrated Monitoring Program across six Natural Management Regions provides a potential opportunity to develop a data-driven understanding of catchment characteristics affecting water quality at the catchment scale. This requires a robust and reliable modelling tool to relate the monitoring data to anthropogenic and natural processes.
\end{abstract}

In this study, monitoring data of Total Suspended Solids (TSS) and dissolved Oxidised Nitrogen ( $\mathrm{NO}_{\mathrm{x}}$ ) from 32 sites across the Great Barrier Reef catchments are selected as case study constituents due to the high risk they pose to reef health when exported from catchments to the receiving marine environment. Also, these two constituents have distinct biogeochemical processes in catchments. Specifically, TSS is typically conserved (although mobilized and deposited) while travelling through river systems; while $\mathrm{NO}_{\mathrm{X}}$ can be potentially processed and removed from the system altogether. A Bayesian hierarchical linear modelling framework is adopted, due to its ability to borrow strength among sites, allowing information to be transferred across space, and due to its ability to provide uncertainty of the predictions. The Bayesian hierarchical linear regression model in this study is developed to evaluate the significance of various catchment characteristics (e.g., land uses, catchment topography and geology) on spatial variation in water quality.

The main findings of this study are listed as follows,

- Sites located in the Burdekin and Fitzroy Natural Management Regions tend to have greater TSS concentrations, illustrated by the modelled site-specific spatial random effects (deviation from the overall average concentration). Additionally, grazing and dry land agriculture land uses are positively correlated with the spatial random effect on TSS. The complexity of interaction between different catchment characteristics (e.g., land use and topography) can potentially result in a negative spatial random effect on TSS, which is reduced in the relatively steeper Great Barrier Reef catchments with a denser stream network.

- Sugar cane is one of the most significant $\mathrm{NO}_{\mathrm{X}}$ contributors according to the modelling results, likely partially due to the excessive application of fertilizers; however, conservation land use has limited effect on $\mathrm{NO}_{\mathrm{X}}$ removal, indicating denitrification process alone may not be sufficient to remove $\mathrm{NO}_{\mathrm{X}}$.

The modelling results demonstrate different land management strategies are required for the purpose of reducing different constituents. This work will provide scientific insights for water quality management at the catchment scale.

Keywords: $\quad$ Water quality, land use, Suspended Solids, Oxidised Nitrogen, Bayesian hierarchical modelling 
Liu et, al., Modelling the impact of land use and catchment characteristics on stream water quality using a Bayesian hierarchical modelling approach in the Great Barrier Reef catchments

\section{INTRODUCTION}

In coastal areas around the world, coral reefs are being degraded. In an Australian context, the coral cover in the Great Barrier Reef has declined significantly, due to a range of threats. Water quality degradation is one of these threats. The Great Barrier Reef marine ecosystem has been experiencing significant water quality deterioration due in part to agricultural intensification and urban settlement in adjacent catchments. The degradation of water quality in rivers draining into the Great Barrier Reef is primarily caused by agricultural land-derived, non-point source pollutants including fine sediments, nutrients and pesticides (Brodie et al., 2013). There is an evident link between elevated terrestrial runoff carrying pollutants, and the degradation of coral reefs in the Great Barrier Reef lagoon (Thorburn et al., 2013). However, water quality in streams is highly variable across space and time, and many factors influence water quality dynamics and pollutant generation and transport, so managing it is a challenge.

Differences in land use and catchment characteristics are likely to be responsible, in part, for spatial variability in water quality, therefore it is important to understand the link between land use and catchment characteristics, and water quality behavior. In this study, we use a Bayesian hierarchical modelling (BHM) framework to investigate the effects of land use and catchment characteristics on spatial variability in water quality. Bayesian Hierarchical Modelling has been implemented in complex ecological and environmental studies, to understand the complex interrelated nature of multivariate systems (Wan et al., 2014). Bayesian hierarchical modelling can provide estimates of the uncertainty in model predictions. This is because it can consider uncertainties in the model parameters, observed data, and discrepancies between model structures and true natural processes. Therefore, estimates are more reliable and can provide insights into decision-making (e.g., water quality management policy) under scenarios with high uncertainty.

In this study, spatial variability in Total Suspended Solid (TSS) and Oxidised Nitrogen (NOX, a major form of Dissolved Inorganic Nitrogen) across 32 water quality monitoring sites is evaluated using a Bayesian Hierarchical Modelling framework. The two constituents are selected for different reasons. Fine sediments (often derived from soil erosion) results in a reduction in the light that is essential for organisms in marine ecosystems, including seagrass and coral. Fine particulate sediments and organic rich flocculent masses can also smother marine organisms (Brodie et al., 2013). $\mathrm{NO}_{\mathrm{X}}$ is closely linked to the decline in coral cover, since excessive $\mathrm{NO}_{\mathrm{X}}$ facilitates outbreaks of the crown-of-thorns starfish, a major coral predator, and also the occurrence of coral bleaching (Hoegh-Guldberg, 1999). They are also controlled by different processes within the catchment so should exhibit contrasting behaviors.

This paper aims to investigate the complex influences of land use and catchment characteristics on water quality under uncertainties. This can inform the design of land management practices that aims to reduce pollutant loads and protect the marine ecosystem.

\section{METHODOLOGY}

\subsection{Study area and materials}

In GBR catchments, there are six Natural Resource Management (NRM) regions (Figure 1). Climate within the GBR catchment ranges from tropical to subtropical, with highly variable rainfall across the

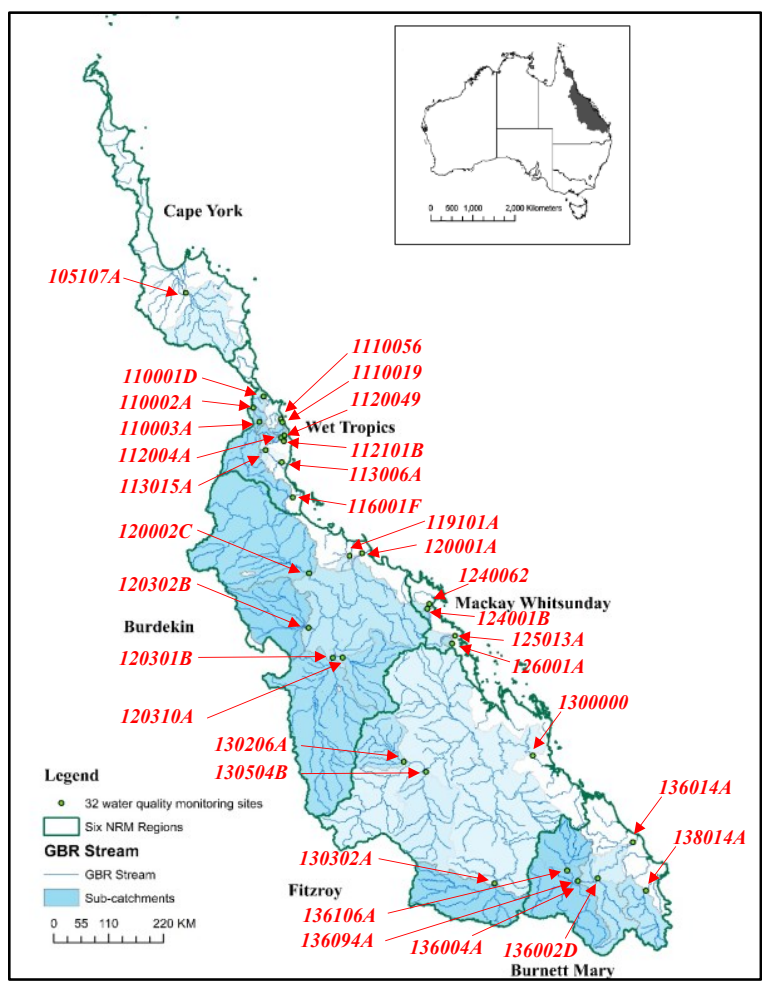

Figure 1. Location of 32 water quality monitoring sites in the Great Barrier Reef catchments area. Coastal areas (Cape York, Wet Tropics and Mackay-Whitsunday) receive significantly higher rainfall than the inland areas (Burdekin, Fitzroy and Burnett-Mary). Therefore, there is more dense settlement and intensive agricultural landscape in the coastal catchments. 
Liu et, al., Modelling the impact of land use and catchment characteristics on stream water quality using a Bayesian hierarchical modelling approach in the Great Barrier Reef catchments

Thirty-two water quality monitoring sites in the Paddock to Reef Integrated Monitoring Program (Waters et al., 2014) across six Natural Resource Management regions are selected in this study. Event-based water quality monitoring data is obtained from the Paddock to Reef Integrated Monitoring Program, sampled between 2006 and 2016. The selected sites and their corresponding contributing area can be delineated based on stream network database provided by the Geofabric from the Bureau of Meteorology (Bureau of Meteorology, 2011). The locations and corresponding delineated sub-catchment areas for 32 sites are shown in Figure 1. The natural catchment topographic and geological characteristics data were retrieved from the National Environmental Stream Attributes dataset (version 1.1.5) and Queensland government (Bureau of Meteorology, 2011; Queensland Government, 2017). The land use information is derived from a product of the Queensland Land Use Mapping Program (QLUMP), which represents the most recent mapping of land use features according to the Australian Land Use and Management (ALUM) Classification. The detailed information for each catchment characteristic evaluated in this study is listed in Table 1.

Table 1. Description and data source for catchment characteristics

\begin{tabular}{|c|c|c|c|}
\hline $\begin{array}{l}\text { Catchment } \\
\text { characteristics }\end{array}$ & Unit & Description & Data source \\
\hline Conservation & $\%$ & $\begin{array}{l}\text { Land used primarily for conservation purposes, based on maintaining the } \\
\text { essentially natural ecosystems present, such as national park. }\end{array}$ & $\begin{array}{l}\text { Queensland } \\
\text { Government, } 2017\end{array}$ \\
\hline Dryland agriculture & $\%$ & $\begin{array}{l}\text { Land used mainly for primary production based on dryland farming systems } \\
\text { (excluding grazing and sugar cane). }\end{array}$ & $\begin{array}{l}\text { Queensland } \\
\text { Government, } 2017 \\
\end{array}$ \\
\hline Irrigated agriculture & $\%$ & $\begin{array}{l}\text { Land used mostly for primary production based on irrigated farming (excluding } \\
\text { grazing and sugar cane). }\end{array}$ & $\begin{array}{l}\text { Queensland } \\
\text { Government, } 2017 \\
\end{array}$ \\
\hline Intensive uses & $\%$ & $\begin{array}{l}\text { Land subject to extensive modification, generally in association with closer } \\
\text { residential settlement, commercial or industrial uses (e.g. urban, utilities, roads). }\end{array}$ & $\begin{array}{l}\text { Queensland } \\
\text { Government, } 2017\end{array}$ \\
\hline Water & $\%$ & Lake, reservoir/dam, river, channel, marsh/wetland. & $\begin{array}{l}\text { Queensland } \\
\text { Government, } 2017\end{array}$ \\
\hline Grazing & $\%$ & $\begin{array}{l}\text { Grazing native vegetation, Grazing modified pastures (Native/exotic pasture } \\
\text { mosaic, Woody fodder plants), Grazing irrigated modified pastures. }\end{array}$ & $\begin{array}{l}\text { Queensland } \\
\text { Government, } 2017\end{array}$ \\
\hline Sugar cane & $\%$ & Dryland Cropping (sugar), Irrigated cropping (sugar). & $\begin{array}{l}\text { Queensland } \\
\text { Government, } 2017\end{array}$ \\
\hline Slope & $\circ$ & Catchment average slope. & $\begin{array}{l}\text { Bureau of } \\
\text { Meteorology, } 2011\end{array}$ \\
\hline Stream density & $\mathrm{km} / \mathrm{km}^{2}$ & Ratio of total stream segment length of all upstream to the contributing area. & $\begin{array}{l}\text { Bureau of } \\
\text { Meteorology, } 2011 \\
\end{array}$ \\
\hline Soil Erodibility & / & $\begin{array}{l}\text { Degrees of erosion vulnerability using a limited set of locally relevant soil } \\
\text { properties. Considering both surface soil stability and subsoil erodibility. }\end{array}$ & $\begin{array}{l}\text { Queensland } \\
\text { Government, } 2017\end{array}$ \\
\hline
\end{tabular}

\subsection{Data treatment}

The raw water quality measurements are highly right-skewed with positive skewness 35.2 for TSS and 15.2 for $\mathrm{NO}_{\mathrm{x}}$. Therefore, data transformation is required before the Bayesian statistical modelling. The Box-Cox transformation (Box et al., 1964) is one widely used parametric transformation technique to improve normality. The power parameters used for TSS and NOx are 0.0058 and 0.1358 , respectively. After application of BoxCox transformation, the kurtosis and skewness decrease significantly to close to 0 for these two constituents.

\subsection{Bayesian Hierarchical Modelling Structure and Implementation}

Bayesian Hierarchical Modelling decomposes the complex and poorly-understood interactions in the observed data into a series of conditional models, which are linked together by probability relationships, following Bayes' theorem (Webb et al., 2010; Wikle, 2003).

The individual Box-Cox transformed TSS and $\mathrm{NO}_{\mathrm{X}}$ measurements for each water quality site are predictands, and spatial variability of individual pollutants between sites is incorporated within the modelling structure using a linear regression against land use and other catchment characteristics (i.e., catchment slope, stream density and soil erodibility, etc.) as predictors. The detailed model structure is as follows.

Data model: This part of the Bayesian Hierarchical Model specifies the water quality constituent concentration $\left(\mathrm{TSS}\right.$ or $\mathrm{NO}_{\mathrm{x}}$ ) data:

$$
P\left(y_{i, j} \mid \mu_{j}, \sigma^{2}\right) \sim N\left(\mu_{j}, \sigma^{2}\right)
$$

The data-level model assumes that the $i^{\text {th }}$ constituent concentration (TSS or NO $\mathrm{NO}_{\mathrm{x}}$ in the $j^{\text {th }}$ sub-catchment, $y_{i, j}$, follows a normal distribution, with mean $\mu_{j}$ (defined in the process model) and variance $\sigma^{2}$ (a constant estimated by the observations). In that case, $\sigma^{2}$ represents within-site variation, which includes the measurements error and natural variability in concentration levels within site. 
Liu et, al., Modelling the impact of land use and catchment characteristics on stream water quality using a Bayesian hierarchical modelling approach in the Great Barrier Reef catchments

Process model: The mean concentration at a site, $\mu_{j}$ is defined by a constant $\alpha$ combined with a spatial random term $\beta_{i, j}$ (i.e., the deviation from the mean resulting from differences in land use/other natural catchment characteristics).

$$
\mu_{j}=\alpha+\beta_{i, j}
$$

The spatial random effect $\beta_{i, j}$ is assumed to follow a normal distribution with mean $\mu_{\beta, j}$, and variance $\sigma_{\beta}{ }^{2}$.

$$
P\left(\beta_{i, j} \mid \mu_{\beta, j}, \sigma_{\beta}^{2}\right) \sim N\left(\mu_{\beta, j}, \sigma_{\beta}^{2}\right)
$$

The mean spatial effect is modelled as a linear additive function of land use and natural catchment characteristics. Land use categories and catchment characteristics are explanatory covariates:

$$
\mu_{\beta, j}=\gamma_{0}+\sum_{n=1}^{k} \gamma_{n} \times \text { Catchment characteristics }_{\mathrm{n}}(j)
$$

where, $k$ is total number of covariates (i.e., 7 land use and 3 other catchment characteristics) evaluated in this Bayesian Hierarchical Modelling framework. $\gamma_{0}$ is regression intercept parameter, and $\gamma_{n}$ is regression slope parameter for the $n^{\text {th }}$ covariate. The variance term $\sigma_{\beta}{ }^{2}$ accounts for variations in concentration levels and spatial random effects between sites not captured by the site-level covariate predictor. All covariates are $z$-scale standardized (mean=0, standard deviation=1). As such, the magnitude of a coefficient indicates the effect of each covariate relative to other covariates (Wan et al., 2014).

Parameter model: Model parameters $\left(\alpha, \gamma_{0}, \gamma_{n}, \sigma, \sigma_{\beta}\right)$ were assumed to be independent from each other. Noninformative uniform priors were assigned to standard deviations $\left(\sigma, \sigma_{\beta}\right)$ and non-informative normal distribution were assigned as the prior distribution for regression coefficients $\left(\alpha, \gamma_{0}, \gamma_{n}\right)$ that describe the data model and the process model (Gelman, 2006):

$$
\begin{gathered}
p\left(\alpha, \gamma_{0}, \gamma_{n}, \sigma, \sigma_{\beta}\right)=p(\alpha) \cdot p\left(\gamma_{0}\right) \cdot \prod_{n=1}^{k} p\left(\gamma_{n}\right) \cdot p(\sigma) \cdot p\left(\sigma_{\beta}\right) \\
\alpha \sim N(0,0.0001) ; \gamma_{0} \sim N(0,0.0001) ; \gamma_{n} \sim N(0,0.0001), \text { for } k=1,2, \ldots, 10 \\
\sigma \sim \operatorname{Uniform}(0,100) ; \sigma_{\beta} \sim \operatorname{Uniform}(0,100)
\end{gathered}
$$

\section{Model Implementation}

Markov Chain Monte Carlo (MCMC) with Gibbs sampling is used to obtain samples from the posterior probability distribution. The MCMC simulation was implemented in OpenBUGS from R by using R2OpenBUGS package (Sturtz et al., 2010). The model was run with 3 chains, and 10,000 iterations for each chain. The first 5,000 iterations were discarded as 'burn-in' period to allow convergence of the Markov chains, and the remaining iterations were thinned by every 3 iterations (i.e., discard all but every $3^{\text {rd }}$ observation) to reduce the effect of auto-correlation within the Markov chains when estimating the posterior distributions. The convergence of each chain was evaluated using the potential scale reduction factor, Rhat (at convergence, Rhat $\approx 1$ ), along with trace plots of model parameters.

\section{RESULT AND DISCUSSION}

The model converged rapidly after approximately 500 iterations and the Rhat values are close to 1 for all monitored parameters, indicating convergence. The detailed model results and discussions for each of the two constituents are presented as follows.

\subsection{TSS Modelling}

Figure $2 \mathrm{~A}$ and Figure $2 \mathrm{~B}$ depict the distribution of the modelled site-specific spatial random effect $\beta_{, j}$ for TSS and the posterior distributions of regression parameters for each catchment characteristics, respectively. The site-specific spatial random effect is the difference between event-based constituent (TSS or $\mathrm{NO}_{\mathrm{X}}$ ) concentrations and overall average concentration, which can be attributed, in part, to the differences in land uses and other catchment characteristics.

As can be seen in Figure $2 \mathrm{~A}$, sites in the large Burdekin and Fitzroy basins (e.g., posterior median of $\beta_{, j} 2.14$ for 130504B Comet River at Comet Weir, 1.86 for 130206A Theresa Creek at Gregory Highway, 1.04 for 120002C Burdekin River at Sellheim and 0.92 for120302B Cape River at Taemas) have a large positive deviation from the average TSS concentration, indicating a higher risk of TSS for these catchments during flow 
Liu et, al., Modelling the impact of land use and catchment characteristics on stream water quality using a Bayesian hierarchical modelling approach in the Great Barrier Reef catchments

events. The land use for the majority of sites in the Burdekin and Fitzroy regions is dominated by grazing and dry land agriculture, indicating the significant source of suspended sediment from such land uses. This result is also supported by the findings from a recent modelling study, that grazing land was the largest source of TSS load (45\% of total exported load), and $81 \%$ of sediment generated from grazing land comes from Fitzroy $(30 \%)$ and Burdekin (51\%) catchments (Waters et al., 2014).

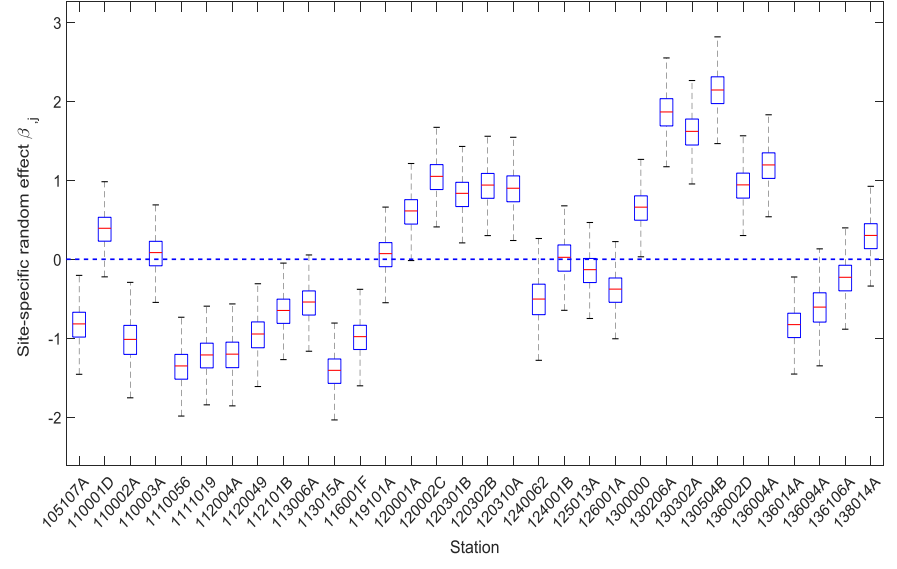

A

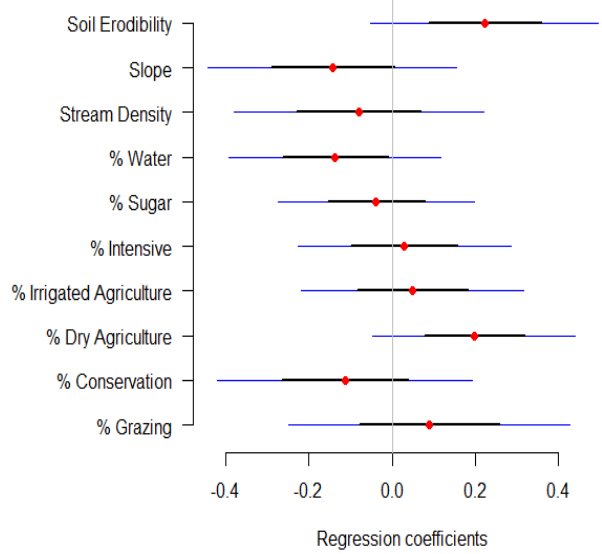

B

Figure 2. Modelling results of TSS modelling. (A) Modelled site-specific random effect $\beta_{, j}$, and red horizontal bar indicating posterior median; (B) Posterior distributions of regression coefficients $\left(\gamma_{n}\right)$ for catchment characteristics in TSS model, and red circles are estimated posterior means, short black lines are $50 \%$ posterior credible intervals and blue lines indicate $95 \%$ credible intervals.

To further quantify the effect of land use and catchment characteristics on spatial variability in TSS, the posterior distribution of the regression coefficients of the catchment characteristics in the site-level model are presented in Figure 2 B. The regression parameters illustrate that catchments with high erodibility and intensive cropping and grazing activities, experienced higher TSS concentrations in streams. The average catchment soil erodibility (mean \pm standard deviation of coefficient $0.22 \pm 0.14)$ and proportion of dry land agriculture $(0.20$ \pm 0.12 ) provide the most significant positive contribution to spatial variability, followed by the proportion of the catchment used for cattle grazing. Higher soil erodibility is more likely to result in higher rates of soil erosion, leading to an increase in hillslope erosion. This is the major source of fine sediment, supported by the utility of soil erodibility dataset in Universal Soil Loss Equation (USLE) (Renard et al., 1997). Percentage of conservation land, catchment slope and stream density have negative effect on deviation of TSS from the mean concentration, but these effects are smaller and the $50 \%$ credible intervals of all these parameters cross the 0 line of 'no effect'. Sub-catchments with steeper slopes and denser stream network tend to have lower TSS concentration during the sampled events. This contrasts with previous studies which state that there is a positive correlation between catchment slope and suspended solids concentrations in streams, due to higher runoff velocity and greater erosion processes ( $\mathrm{Yu}$ et al., 2016). The effect of slope and stream density on TSS illustrated by the modelling results could be explained by complexity in the interactions between different catchment characteristics. For example, most of the flat catchments in this study are located in inland catchments (e.g., the Fitzroy and Burdekin), where large areas with a high percentage of grazing might act as a source of sediment. Therefore, higher TSS concentrations were observed compared with coastal steeper catchments in Wet Tropics, Burnett Mary and Cape York regions, consistent with the findings from Varanka et al. (2015) and Ye et al. (2009).

\subsection{NOx Modelling}

The site-specific spatial variability in $\mathrm{NO}_{\mathrm{X}}$ is demonstrated by Figure 3 A. For several sites, the modelled median NOx concentration is completely above zero. These sites are located in coastal downstream regions, such as the Wet Tropics (e.g., median $\beta_{, j}$ of 0.57 for 110003A Barron River at Picnic Crossing, 0.52 for 1111019 (Brodie, 2006)Russell River at East Russell, 0.59 for 113006A Tully River at Euramo), Mackay Whitsunday (e.g., 0.89 for 126001A Sandy Creek at Homebush and 0.51 for 125013A Pioneer River at Dumbleton Pump Station). In these regions, there is a high percentage of sugar cane cropping $(>8 \%)$ in the catchments. 
Liu et, al., Modelling the impact of land use and catchment characteristics on stream water quality using a Bayesian hierarchical modelling approach in the Great Barrier Reef catchments

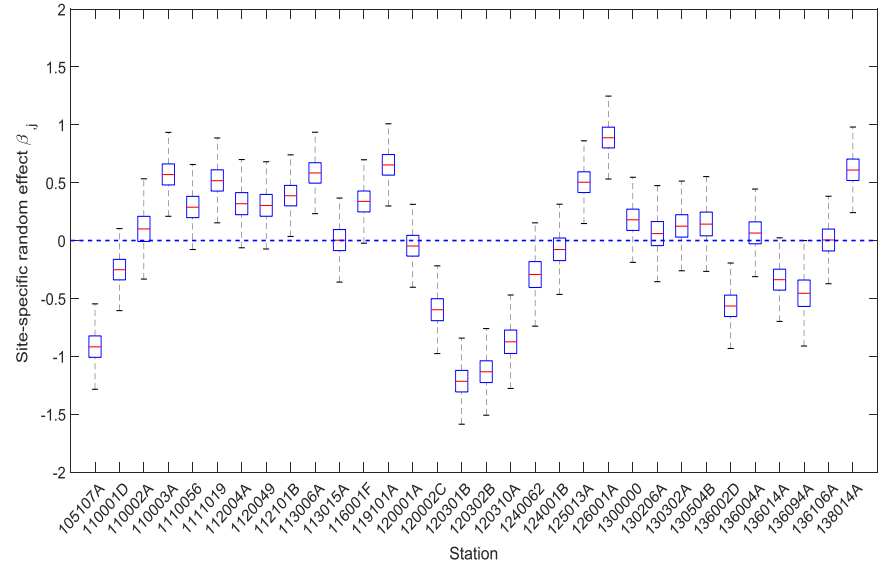

A

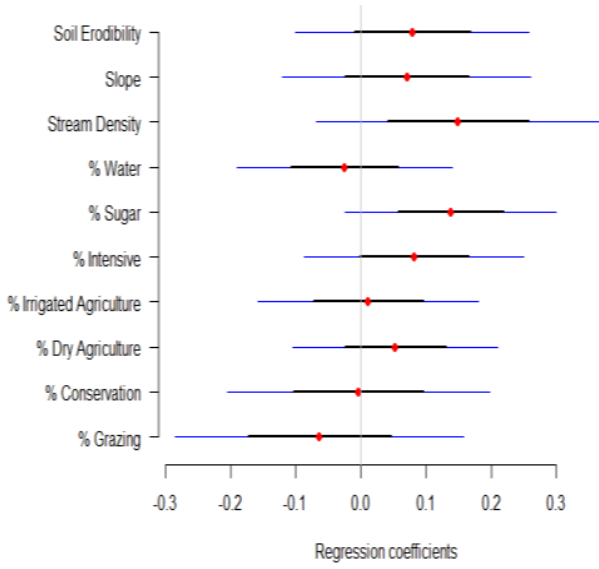

B

Figure 3. Modelling results of $\mathrm{NO}_{\mathrm{X}}$ modelling. (A) Modelled site-specific random effect $\beta_{, j}$, and red

horizontal bar indicating posterior median; (B) Posterior distributions of regression coefficients $\left(\gamma_{n}\right)$ for catchment characteristics in $\mathrm{NO}_{\mathrm{X}}$ model, and red circles are estimated posterior means, short black lines are $50 \%$ posterior credible intervals and blue lines indicate $95 \%$ credible intervals

Indeed, the posterior distributions of the regression coefficients in Figure 3 B indicate that, sugar cane is one of the most significant factors leading to increased $\mathrm{NO}_{\mathrm{X}}$. The $50 \%$ credible interval for sugar cane land use regression coefficient of 0.057 to 0.219 indicate a positive correlation between sugar cane and in-stream $\mathrm{NO}_{\mathrm{X}}$ concentrations. Brodie (2006) shows that typically high percentage of the $\mathrm{N}$ source for sugar cane is nitrogenous fertilizer. The strong effect of sugar cane cropping together with this suggests that nitrogenous fertilizer is likely to be the main source of NOx in stream. The mean regression coefficient of conservation land is close to 0 , indicating its limited effect of this land use on $\mathrm{NO}_{\mathrm{X}}$ removal. A regional study conducted by Connor et al. (2013) revealed that high dissolved inorganic nitrogen in humid tropics areas in Queensland, occurs because denitrification may not be sufficient to remove $\mathrm{NO}_{\mathrm{X}}$. The positive effects of stream density and slope in Figure $3 \mathrm{~B}$ (posterior mean of 0.15 and 0.06 , respectively) indicates that $\mathrm{NO}_{\mathrm{X}}$ can be transported through drainage networks. These effects might reduce the residence time and retention effect in the soil for plant uptake, leaching to subsurface flow and denitrification.

\subsection{Management Implications}

The models indicate that the catchment characteristics influencing in-stream TSS and $\mathrm{NO}_{\mathrm{X}}$ concentrations are different. Therefore, different management strategies are needed for the two constituents. Specifically, to reduce in-stream TSS concentrations, grazing and dry land agriculture land uses should be targeted. Management strategies, such as fencing by land type and riparian re-vegetation in order to manage the land types of different vulnerability and improve the riparian vegetation restoration. In addition, management of vulnerable streambank and floodplain, such as installation of off stream watering points, enables grazing pressure to be distributed more evenly, and reduces the risk of streambank erosion. To reduce $\mathrm{NO}_{\mathrm{X}}$ concentration in streams, management of fertilizer application on cropping lands (e.g., sugar cane) should be addressed. In particular, strategies such as applying only the necessary amount of fertilizer, applying this fertilizer at the appropriate time and control traffic, should be adopted. These results are consistent with expectations that the current BMPs can reduce the water quality impacts from agriculture.

\section{CONCLUSION}

This paper reveals the ability of Bayesian hierarchical regression models to evaluate the relationship between land use and other catchment characteristics and two water quality indicators (TSS and $\mathrm{NO}_{\mathrm{x}}$ concentrations) in the Great Barrier Reef catchments. The effects of land use and catchment characteristics are estimated with uncertainties, which is essential for informing the practice management strategies aiming at pollutant reduction. The modelling results illustrate grazing and dry land agriculture land uses are the most relevant to spatial variation in in-stream TSS concentration; while, sugar cane land use is by far the most significant $\mathrm{NO}_{\mathrm{X}}$ contributor. A data-driven understanding of controls on site-level spatial variation in pollutants concentration facilitates the prioritization of best management practices to address the deterioration of terrestrial runoff. We found that the current adopted BMPs in the Great Barrier Reef catchment are in line with results of the Bayesian 
Liu et, al., Modelling the impact of land use and catchment characteristics on stream water quality using a Bayesian hierarchical modelling approach in the Great Barrier Reef catchments

hierarchical modelling, suggesting that the current mitigation strategies are appropriate for reducing TSS and $\mathrm{NO}_{\mathrm{X}}$ concentrations in the Great Barrier Reef catchment streams. Future study opportunities involve incorporation of temporal covariate in data-level of the Bayesian hierarchical model to better capture the temporal variability in water quality; meanwhile, developing event mean concentration for individual event would be a potential way to better relate catchment antecedent conditions and catchment characteristics.

\section{ACKNOWLEDGEMENT}

This study was supported by the Australian Research Council (LP140100495), the Victorian EPA, the Victorian Department Land for Environment Water and Planning, Bureau of Meteorology and Queensland Natural Resources and Mines. The authors would like to acknowledge the efforts of the Queensland Department of Natural Resources and Mines who has provided water quality monitoring data.

\section{REFERENCES}

Box, G. E., \& Cox, D. R. (1964). An analysis of transformations. Journal of the Royal Statistical Society. Series $B$ (Methodological), 211-252.

Brodie, J. (2006). Nutrient management zones in the Great Barrier Reef catchment: a decision system for zone selection: Australian Centre for Tropical Freshwater Research.

Brodie, J., Waterhouse, J., Schaffelke, B., Johnson, J., Kroon, F., Thorburn, P., Rolfe, J., Lewis, S., Warne, M., \& Fabricius, K. (2013). Reef water quality scientific consensus statement 2013. Department of the Premier and Cabinet, Queensland Government, Brisbane.

Bureau of Meteorology, G. A. (2011). Environmental Attributes Database. Retrieved 15/03/2016 http://www.ga.gov.au

Connor, S., Nelson, P., Armour, J., \& Hénault, C. (2013). Hydrology of a forested riparian zone in an agricultural landscape of the humid tropics. Agriculture, ecosystems \& environment, 180, 111-122.

Gelman, A. (2006). Prior distributions for variance parameters in hierarchical models (comment on article by Browne and Draper). Bayesian analysis, 1(3), 515-534.

Hoegh-Guldberg, O. (1999). Climate change, coral bleaching and the future of the world's coral reefs. Marine and Freshwater Research, 50(8), 839-866.

Queensland Government, S. I. T. a. I. (2017). Mapping erodible soils in Burdekin Dry Tropics grazing lands series.

Renard, K. G., Foster, G. R., Weesies, G., McCool, D., \& Yoder, D. (1997). Predicting soil erosion by water: a guide to conservation planning with the Revised Universal Soil Loss Equation (RUSLE) (Vol. 703): US Government Printing Office Washington, DC.

Sturtz, S., Ligges, U., \& Gelman, A. (2010). R2OpenBUGS: a package for running OpenBUGS from R. URL http://cran. rproject. org/web/packages/R2OpenBUGS/vignettes/R2OpenBUGS. pdf.

Thorburn, P., Wilkinson, S., \& Silburn, D. (2013). Water quality in agricultural lands draining to the Great Barrier Reef: a review of causes, management and priorities. Agriculture, ecosystems \& environment, 180, 4-20.

Varanka, S., Hjort, J., \& Luoto, M. (2015). Geomorphological factors predict water quality in boreal rivers. Earth Surface Processes and Landforms, 40(15), 1989-1999.

Wan, R., Cai, S., Li, H., Yang, G., Li, Z., \& Nie, X. (2014). Inferring land use and land cover impact on stream water quality using a Bayesian hierarchical modeling approach in the Xitiaoxi River Watershed, China. Journal of Environmental Management, 133, 1-11.

Waters, D., Carroll, C., Ellis, R., Hateley, L., McCloskey, G., Packett, R., Dougall, C., \& Fentie, B. (2014). Technical Report Modelling Reductions of Pollutant Loads Due to Improved Management Practices in the Great Barrier Reef Catchments-Whole of GBR, vol. 1. Queensland Department of Natural Resources and Mines, Toowoomba, Queensland.

Webb, J. A., Stewardson, M. J., \& Koster, W. M. (2010). Detecting ecological responses to flow variation using Bayesian hierarchical models. Freshwater Biology, 55(1), 108-126.

Wikle, C. K. (2003). Hierarchical Models in Environmental Science. International Statistical Review, 71(2), 181-199.

Ye, L., Cai, Q.-h., Liu, R.-q., \& Cao, M. (2009). The influence of topography and land use on water quality of Xiangxi River in Three Gorges Reservoir region. Environmental Geology, 58(5), 937-942.

Yu, S., Xu, Z., Wu, W., \& Zuo, D. (2016). Effect of land use types on stream water quality under seasonal variation and topographic characteristics in the Wei River basin, China. Ecological Indicators, 60, 202-212. 